\title{
Adsorption Equilibrium and Kinetics of the Removal of Ammoniacal Nitrogen by Zeolite X/Activated Carbon Composite Synthesized from Elutrilithe
}

\author{
Yong Zhang, ${ }^{1}$ Feng Yu, ${ }^{2}$ Wenping Cheng, ${ }^{2}$ Jiancheng Wang, ${ }^{3}$ and Juanjuan $\mathrm{Ma}^{1}$ \\ ${ }^{1}$ College of Water Resource Science and Engineering, Taiyuan University of Technology, Taiyuan 030024, China \\ ${ }^{2}$ College of Chemistry and Chemical Engineering, Taiyuan University of Technology, Taiyuan 030024, China \\ ${ }^{3}$ State Key Laboratory Breeding Base of Coal Science and Technology Co-Founded by Shanxi Province and the Ministry of \\ Science and Technology, Taiyuan University of Technology, Taiyuan 030024, China
}

Correspondence should be addressed to Feng Yu; yufeng@tyut.edu.cn and Juanjuan Ma; mjjsxty@163.com

Received 5 December 2016; Revised 26 January 2017; Accepted 1 February 2017; Published 27 March 2017

Academic Editor: Mu. Naushad

Copyright (C) 2017 Yong Zhang et al. This is an open access article distributed under the Creative Commons Attribution License, which permits unrestricted use, distribution, and reproduction in any medium, provided the original work is properly cited.

\begin{abstract}
Zeolite X/activated carbon composite material (X/AC) was prepared from elutrilithe, by a process consisting of carbonization, activation, and subsequent hydrothermal transformation of aluminosilicate in alkaline solution, which was used for the removal of ammoniacal nitrogen from aqueous solutions. Adsorption kinetics, equilibrium, and thermodynamic were studied and fitted by various models. The adsorption kinetics is best depicted by pseudosecond-order model, and the adsorption isotherm fits the Freundlich and Redlich-Peterson model. This explains the ammoniacal nitrogen adsorption onto X/AC which was chemical adsorption in nature. Thermodynamic properties such as $\Delta G, \Delta H$, and $\Delta S$ were determined for the ammoniacal nitrogen adsorption, and the positive enthalpy confirmed that the adsorption process was endothermic. It can be inferred that ammoniacal nitrogen removal by $\mathrm{X} / \mathrm{AC}$ composite is attributed to the ion exchange ability of zeolite X. Further, as a novel sorbent, this material has the potential application in removing ammoniacal nitrogen coexisting with other organic compounds from industrial wastewater.
\end{abstract}

\section{Introduction}

Water pollution, such as heavy metals, dyes, organic, and inorganic pollutants, is a serious problem for the human being with the rapid urbanization, industrialization, and technological innovations in various disciplines. Many researchers have developed different methods and materials to remove the contaminants [1-7]. Among them, high concentration of ammonium ions is the a major pollutant and is harmful to animal and human health and also attacks the water plumbing systems [8]. The removal of ammoniacal nitrogen has attracted great attention in wastewater treatment.

For the water treatment, several methods such as chemical precipitation, biological processes, ion exchange, and adsorption have been taken and applied to the removal of ammoniacal nitrogen from wastewater [9-12]. Among these technologies, biological processes as one of the most widely used technologies are effective for wastewater with low concentration ammonium ions but require complicated configurations and process routing. However, the biological processes are usually helpless in dealing with the solution containing high concentration ammonium ions. So, the drive to remove the ammoniacal nitrogen with high concentration has motivated a significant increase in research activities. Compared with the other methods, ion exchange is more attractive owing to the advantages of simple operation and high effectiveness $[13,14]$.

Due to the excellent ion exchange ability and high surface area, natural zeolites $[15,16]$ and synthetic zeolites $[17,18]$ are employed to remove the ammoniacal nitrogen from aqueous solution by the ion exchange method. Karadag et al. [19] and Huang et al. [20] demonstrated that both the natural Turkish clinoptilolite and Chinese zeolite had strong ability to remove 
ammonium from aqueous solutions. In recent years, many researchers have investigated ammoniacal nitrogen removal from aqueous solutions by using eco-friendly material, such as the zeolites derived from agricultural waste, fly ash, or industrial waste. For example, Yusof et al. [21] reported that zeolite Y synthesized from rice husk ash waste was found to have higher adsorption capacity than mordenite for ammonium removal, and the equilibrium isotherm proved its monolayer adsorption. Mishra and Tiwari [22] found that zeolite $13 \mathrm{X}$ originated from Indian fly ash had a good sorption property for metal ions at acidic $\mathrm{pH}$. However, the collection and processing of these raw materials are the major engineering problems to be solved in the case of commercializing those waste-originated zeolites.

Elutrilithe, an unusable solid waste, is widely discharged and piled up outside the coal mines in China. Moreover, the number is a steady increase of about 130 million tons each year $[23,24]$. So much solid waste not only occupies a large area of farmland but also causes ecological damage, such as air pollution and water pollution. However, elutrilithe is a kaolinite-rich gangue containing aluminosilicate, according to the chemical composition of the raw material, and zeolites/activated carbon composites can be obtained, by a process consisting of carbonization, activation, and subsequent hydrothermal transformation of aluminosilicate in alkaline solution [25]. This composite material has the combination of the adsorptive properties of zeolite and activated carbon, and its applications have emerged in the wastewater treatment industries [26]. In our previous work, phenol adsorption on $\mathrm{X} / \mathrm{AC}$ composite material has been studied, and this material showed an excellent adsorption capacity attributed to the existence of activated carbon [27]. However, the removal of ammoniacal nitrogen by this composite has not been reported.

So, this work aims to realize the value of zeolite X/activated carbon composite synthesized from solid waste on the removal of ammoniacal nitrogen from aqueous solutions. The optimal values of $\mathrm{pH}$, temperature, and initial concentration were used for the batch experiments. In addition, the kinetic and equilibrium behaviors of the composite were investigated and several adsorption models such as Langmuir, Freundlich, and Redlich-Peterson were adopted to fit the adsorption isotherm. The adsorption kinetic rates were calculated to evaluate the possible adsorption mechanisms. The material has a significant potential in removing ammoniacal nitrogen coexisting with phenolic compounds from wastewater.

\section{Materials and Methods}

2.1. Preparation of Composite Materials. The preparation of zeolite X/activated carbon composite was based on the procedure reported by Ma et al. [25]. The following is a typical synthesis example: the mixture of elutrilithe and $35 \mathrm{wt} \%$ of pitch was used as starting material and extruded into cylinders $(3.0 \mathrm{~mm} \times 6.0 \mathrm{~mm})$. The extrudate was carbonized by $\mathrm{N}_{2}$ and then activated using $\mathrm{CO}_{2}$ at $850^{\circ} \mathrm{C}$ for $24 \mathrm{~h}[27,28]$. After that, zeolite $13 \mathrm{X}$ was formed by hydrothermally treatment in $\mathrm{NaOH}$ solution at $65^{\circ} \mathrm{C}$ for $12 \mathrm{~h}$, followed by $90^{\circ} \mathrm{C}$ for
$24 \mathrm{~h}$ under stirring. Thus, the zeolite $13 \mathrm{X} /$ activated carbon composite was obtained and named as X/AC, in which the contents of $\mathrm{SiO}_{2}, \mathrm{Al}_{2} \mathrm{O}_{3}$, and carbon were $29 \%, 20 \%$, and $18 \%$, respectively.

2.2. Characterization of Material. The X-ray diffraction (XRD) patterns of the material were recorded on Shimadzu $\mathrm{XRD}-6000$ with $\mathrm{Cu} \mathrm{K} \alpha$ radiation at the $2 \theta$ of $20^{\circ}-70^{\circ}$, in steps of $8^{\circ}$. Nitrogen adsorption and desorption isotherms were measured at $-196^{\circ} \mathrm{C}$ on a Quantachrome analyzer. Before the measurement, the samples were evacuated for $3 \mathrm{~h}$ at $300^{\circ} \mathrm{C}$. The surface area was calculated by Brunauer-EmmettTeller (BET) formula and the pore volume was estimated at the relative pressure of 0.98 . The pore size distribution was derived from the adsorption branch of the isotherm, using the density functional theory (DFT) method. The morphology was analyzed by a Hitachi S-4800 scanning electron microscope.

2.3. Batch Adsorption Experiments. The adsorption isotherms of ammoniacal nitrogen were obtained by batch experiments at different temperatures $\left(30,35\right.$, and $\left.40^{\circ} \mathrm{C}\right)$. For each experiment, $25 \mathrm{~mL}$ of ammoniacal nitrogen solution with different initial concentrations $\left(C_{0}\right)$ and $6 \mathrm{~g} / \mathrm{L}$ of X/AC adsorbent were mixed in a flask. The solution $\mathrm{pH}$ was adjusted to 6.5 by the addition of $\mathrm{NaOH}(0.1 \mathrm{~mol} / \mathrm{L})$ or $\mathrm{HCl}(0.1 \mathrm{~mol} / \mathrm{L})$. The mixture was shaken at $150 \mathrm{rpm}$ for $20 \mathrm{~h}$ in a temperaturecontrolled shaker to ensure equilibrium. Finally, the adsorbent was filtered and the residual concentration of ammoniacal nitrogen was analyzed by Walter [29]. Adsorption kinetics was carried out with the same procedure at $25^{\circ} \mathrm{C}$, the solution $\mathrm{pH}$ value was 6.5 , and the initial ammoniacal nitrogen concentrations were $69,122,280,460$, and $500 \mathrm{mg} / \mathrm{L}$. After different time intervals, the adsorbent was filtered and the residual concentrations were analyzed.

2.4. Adsorption Isotherm. The equilibrium adsorption amount of ammoniacal nitrogen, $q_{e}(\mathrm{mg} / \mathrm{g})$, was calculated by the following formula:

$$
q_{e}=\frac{\left(C_{0}-C_{e}\right) \cdot V}{m},
$$

where $C_{0}$ is the initial concentration of the solution; $C_{e}$ is the concentration at equilibrium; $m$ is the mass of adsorbent. The equilibrium adsorption data was fitted by Langmuir, Freundlich, and Redlich-Peterson models.

2.4.1. Langmuir Adsorption Isotherm. The Langmuir isotherm assumes that the adsorption takes place at specific homogeneous sites on the surface of the adsorbent and form a monomolecular adsorbed layer, which can be expressed as the following equation [30]:

$$
q_{e}=\frac{q_{m} b C_{e}}{1+b C_{e}},
$$

where $q_{m}(\mathrm{mg} / \mathrm{g})$ is the maximum adsorption capacity of the adsorbent and $b(\mathrm{~L} / \mathrm{mg})$ is the Langmuir adsorption equilibrium constant. 
2.4.2. Freundlich Adsorption Isotherm. The Freundlich isotherm provides an empirical isotherm, which assumes that nonideal adsorption takes place on a heterogeneous surface with different adsorption energy and characters [31]:

$$
q_{e}=K_{F} C_{e}^{(1 / n)},
$$

where $K_{F}(\mathrm{mg} / \mathrm{g})(\mathrm{L} / \mathrm{mg})$ and $n$ are Freundlich constants, related to adsorption capacity and adsorption intensity, respectively.

2.4.3. Redlich-Peterson (R-P) Adsorption Isotherm. R-P isotherm proposed by Redlich and Peterson [32] is a combined form of Langmuir and Freundlich expressions. It can be used for predicting homogenous and heterogeneous adsorption systems. The equation is as follows:

$$
q_{e}=\frac{K_{R} C_{e}}{1+a_{R} C_{e}^{\beta}},
$$

where $K_{R}(\mathrm{~L} / \mathrm{g})$ and $\alpha_{R}(\mathrm{~L} / \mathrm{mg})^{\beta}$ are the adsorption R-P constants and $\beta$ is the exponent and ranges between 0 and 1 . When $\beta=0$, the R-P equation reduces to Henry's equation which is a linear isotherm and to the Langmuir isotherm for $\beta=1$. For high adsorbate concentration, the R-P equation reduces to the Freundlich isotherm.

2.5. Adsorption Thermodynamics. The thermodynamic parameters, including change in Gibbs free energy $(\Delta G)$, enthalpy $(\Delta H)$, and entropy $(\Delta S)$, were determined by using following equations and represented as

$$
\begin{aligned}
\Delta G^{0} & =-R T \ln K_{D}, \\
K_{D} & =\frac{q_{e}}{C_{e}}, \\
\ln K_{D} & =\frac{\Delta S^{0}}{R}-\frac{\Delta H^{0}}{R T},
\end{aligned}
$$

where $K_{D}$ is the adsorption equilibrium constant, $\Delta G^{0}$ was given from the classical Van't Hoff equation, and $\Delta H^{0}$ and $\Delta S^{0}$ were calculated from the slope and of $\ln K_{D}$ against $1 / T$. $R$ is the universal gas constant $(8.314 \mathrm{~J} / \mathrm{mol})$ and $T$ is the adsorption temperature $(\mathrm{K})$.

\subsection{Adsorption Kinetics}

2.6.1. Pseudofirst-Order Model. The pseudofirst-order model is depicted as follows [33]:

$$
\frac{d q_{t}}{d t}=k_{1}\left(q_{e}-q_{t}\right)
$$

When integrated under the boundary conditions $t=0$, $q=0$, and $t=t, q=q_{t}$, the equation becomes

$$
\ln \left(q_{e}-q_{t}\right)=\ln q_{e}-k_{1} t
$$

where $k_{1}$ is the pseudofirst-order rate constant and $q_{e}$ and $q_{t}$ are the adsorption capacity of the adsorbent at equilibrium and at time $t$, respectively.

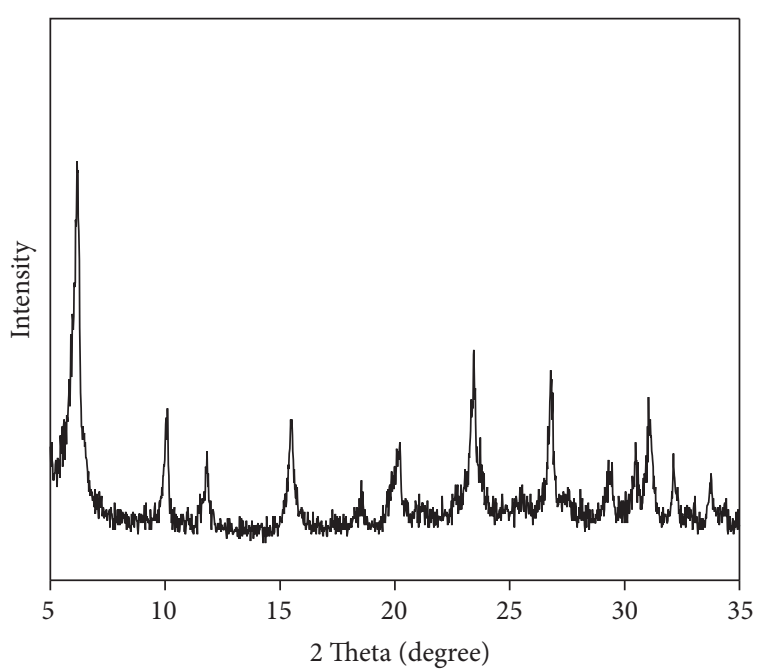

FIGURE 1: XRD patterns of the composite material.

2.6.2. Pseudosecond-Order Model. The pseudosecond-order model can be expressed as follows [34]:

$$
\frac{d q_{t}}{d t}=k_{2}\left(q_{e}-q_{t}\right)^{2}
$$

The linearized-integrated form of the equation is as follows:

$$
\frac{t}{q_{t}}=\frac{1}{k_{2} q_{e}{ }^{2}}+\frac{t}{q_{e}},
$$

where $k_{2}$ is the pseudosecond-order rate constant.

\section{Results and Discussion}

3.1. Adsorbent Characterization. The XRD patterns of the samples are demonstrated in Figure 1. A well-crystallized Xray diffraction pattern of typical zeolite $\mathrm{X}$ is found in the composite $\mathrm{X} / \mathrm{AC}$, which is in agreement with [35]. It is indicated that the zeolite $\mathrm{X} /$ activated carbon composite is successfully prepared from the waste raw materials.

$\mathrm{N}_{2}$ adsorption-desorption isotherms of the composite are shown in Figure 2. As seen from Figure 2, the $\mathrm{N}_{2}$ adsorption-desorption isotherms of X/AC composite exhibit both type I and IV isotherms, corresponding to hierarchical porosity ranging from micropore, mesopore, to macropore. The specific BET surface area and the total pore volume are $888 \mathrm{~m}^{2} / \mathrm{g}$ and $0.63 \mathrm{~cm}^{3} / \mathrm{g}$, respectively. This result is much higher than the untreated elutrilithe, attributing to the formation of zeolite $13 \mathrm{X}$ from the aluminosilicate in the raw material by the hydrothermal crystallization.

The scanning electron microscopy (SEM) images of the samples are given in Figure 3. As demonstrated from Figure 3, the prepared $\mathrm{X} / \mathrm{AC}$ material has the features of $13 \mathrm{X}$ and activated carbon. From the magnifying image of Figure 3(b), octahedral structure of $13 \mathrm{X}$ and rough structure of activated carbon coexisted, which confirms the $13 \mathrm{X}$ zeolite has been successfully prepared, and the crystal aggregates have been 


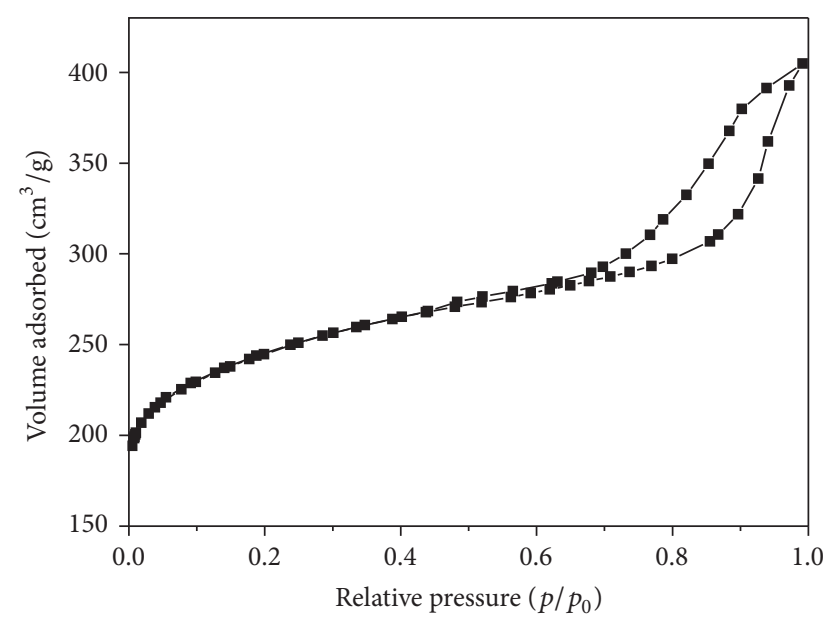

FIGURE 2: $\mathrm{N}_{2}$ adsorption-desorption isotherms of the composite material.

covered by activated carbon. Furthermore, the surface of activated carbon in $\mathrm{X} / \mathrm{AC}$ is looser and more porous compared with the raw material.

3.2. Effect of the Solution $p H$. The adsorption capacities of ammoniacal nitrogen in the $\mathrm{pH}$ range of 3.2-8.5 were performed and given in Figure 4. The maximum adsorption amount of ammoniacal nitrogen was achieved when the experiment was operated at $\mathrm{pH} 6.5$. The $\mathrm{pH}$ has an important effect on ammoniacal nitrogen removal since it can impact the character of ammonium ion. When the $\mathrm{pH}$ value is higher than 7 , the adsorption capacities of ammoniacal nitrogen decrease, because the ammonium ion is transformed to nonionized forms of ammonia gas, which is unfavorable for adsorption on $\mathrm{X} / \mathrm{AC}$ composite [36-38]. When the $\mathrm{pH}$ is lower, ammonium ions compete with hydrogen ions on the adsorption sites. Hence, in this study, the $\mathrm{pH}$ of 6.5 is selected as the optimum $\mathrm{pH}$ on ammoniacal nitrogen adsorption.

3.3. Adsorption Isotherms. The composite was made into particles with the size of 20 60 mesh as adsorbent for ammonium. In a $100 \mathrm{~mL}$ beaker, the composite was added to $25 \mathrm{~mL} \mathrm{NH}_{4} \mathrm{Cl}$ solution with a ration of $6 \mathrm{~g} / \mathrm{L}$. The $\mathrm{pH}$ value of the solution was adjusted to 6.5 , and the time for adsorption is $12 \mathrm{~h}$. The thermodynamics and kinetics of the adsorption were studied by evaluating the effect of adsorption time and initial concentration.

Adsorption temperature and initial concentration affected the adsorption significantly. The concentration at equilibrium point and the rate of adsorption were affected by the initial concentration and temperature. The adsorption isotherms at the temperatures of 30,35 , and $40^{\circ} \mathrm{C}$ were shown in Figure 5. With the same initial concentration, the adsorption increased when the temperature was increased. At the concentration of $151.73 \mathrm{mg} / \mathrm{L}$, the uptake of ammonium was $15.55,17.44$, and $19.02 \mathrm{mg} / \mathrm{g}$, respectively, when the temperature was 30,35 , and $40^{\circ} \mathrm{C}$. The removal of ammonium from solution by the composite of X/AC originated from the ion exchange by zeolite. The effectiveness and efficiency of this material are close to the fly ash and $13 \mathrm{X}$ reported by Zheng et al. [7] and Zhang et al. [18]. This result demonstrates that ammoniacal nitrogen removal by this new composite synthesized from elutrilithe is feasible. Moreover, the process of ion exchange [39] is endothermic, which explains the result that the adsorption of ammoniacal nitrogen increased as the temperature increased. At the same temperature, the uptake increased when the concentration rose. With the same adsorption time, the solution with higher concentration could result in bigger difference of concentration between that in the solution and that in the adsorbent, which offered higher driving force for the ion exchange, and increased the efficiency of adsorption.

Three different models (Langmuir, Freundlich, and Redlich-Peterson (R-P)) were applied to fit the adsorption isotherms. The isotherm parameters, the values of the correlation coefficient $R^{2}$, and the statistical error RSME are summarized in Table 1 . The values of $R^{2}$ of Langmuir model in the range of 0.9221-0.9571 are relatively low, which cannot describe the experimental data accurately. Moreover, the composite of X/AC does not have homogeneous surface, and the adsorption of ammonium is not in a monolayer. So Langmuir model does not apply in this case. The values of $R^{2}$ are higher for Freundlich and R-P model than that of Langmuir model, indicating that Freundlich and R-P model give the better fitting in the adsorption of ammoniacal nitrogen on X/AC. The Freundlich constant $K$ increased with the increasing of the temperature, implying that adsorption of ammoniacal nitrogen is endothermic, Freundlich constant $n$ was less than 1 revealing that the surface of X/AC is heterogeneous. Also, R-P model works in the situation of a wide range of concentration, explaining solid surface adsorption is heterogeneous. Further, the calculation of statistical error RMSE was also performed. The RMSE results indicate that the fitted data of Freundlich and Redlich-Peterson model are close to the actual value, it is superior to the Langmuir model, and the results are in a good agreement with the result of $R^{2}$.

3.4. Adsorption Thermodynamics. The adsorption equilibrium isotherms of ammoniacal nitrogen can be described better by R-P model. The values of $K_{D}$ are obtained from R-P adsorption isotherm, according to literature [27]. In a study of the adsorption process in environmental engineering, Gibbs free energy $\left(\Delta G^{0}\right)$, enthalpy change $\left(\Delta H^{0}\right)$, and entropy change $\left(\Delta S^{0}\right)$ are normally evaluated to judge whether an adsorption of an adsorbate on an adsorbent can happen spontaneously or not. These parameters can be calculated from the graph of $\ln K_{D}$ versus $1 / T$, which are listed in Figure 6 and Table 2. The free energy changes $\left(\Delta G^{0}\right)$ obtained were -36.81 , -37.41 , and $-38.02 \mathrm{~kJ} / \mathrm{mol}$ at 30,35 , and $40^{\circ} \mathrm{C}$, respectively. When the value of $\Delta G^{0}$ is negative, adsorption can happen by itself. On the other hand, when the value of $\Delta G^{0}$ is positive, adsorption cannot happen spontaneously. The negative values of $\Delta G^{0}$ indicate the spontaneous nature of ammonium uptake by the X/AC composite. The enthalpy change $\left(\Delta H^{0}\right)$ of adsorption was obtained as $24.44 \mathrm{~kJ} / \mathrm{mol}$. The positive value of $\Delta H^{0}$ means the adsorption process is an endothermic nature [26]. This is in agreement with the expected higher 


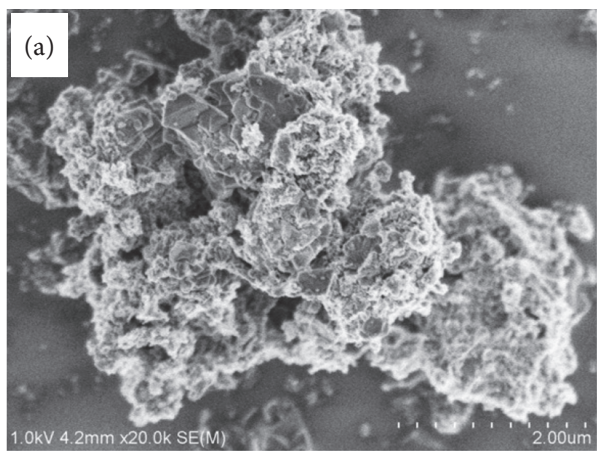

(a)

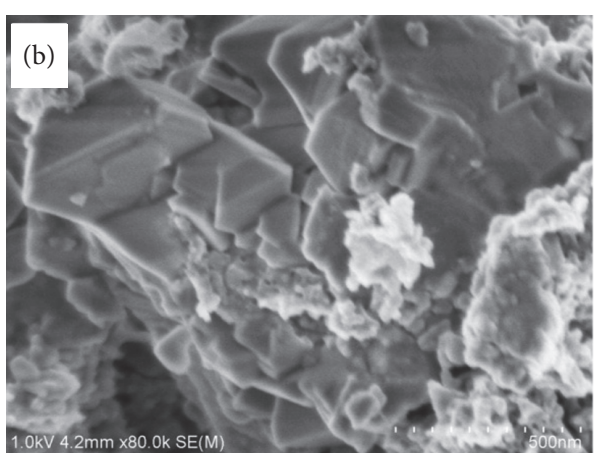

(b)

FIGURE 3: SEM images of the composite material.

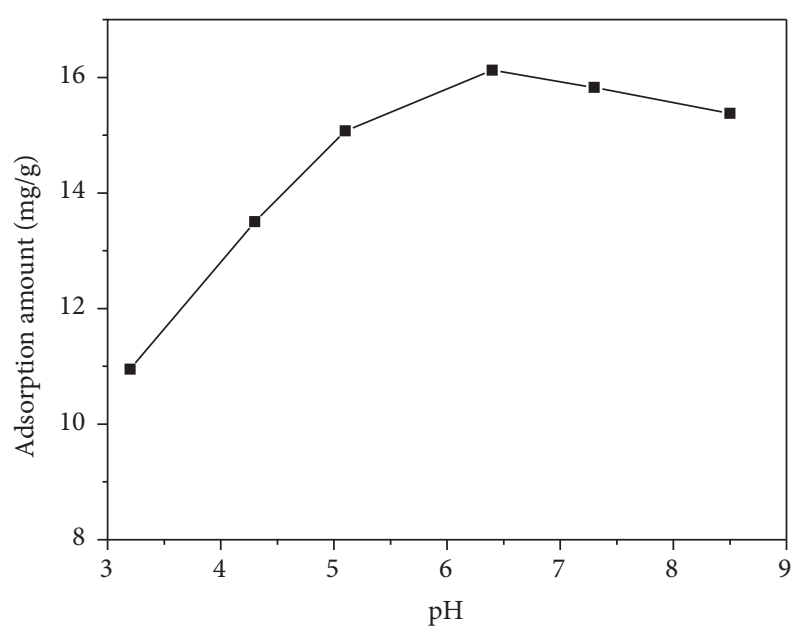

FIGURE 4: Effect of initial $\mathrm{pH}$ on ammoniacal nitrogen adsorption on $\mathrm{X} / \mathrm{AC}$ composite at $298 \mathrm{~K}$.

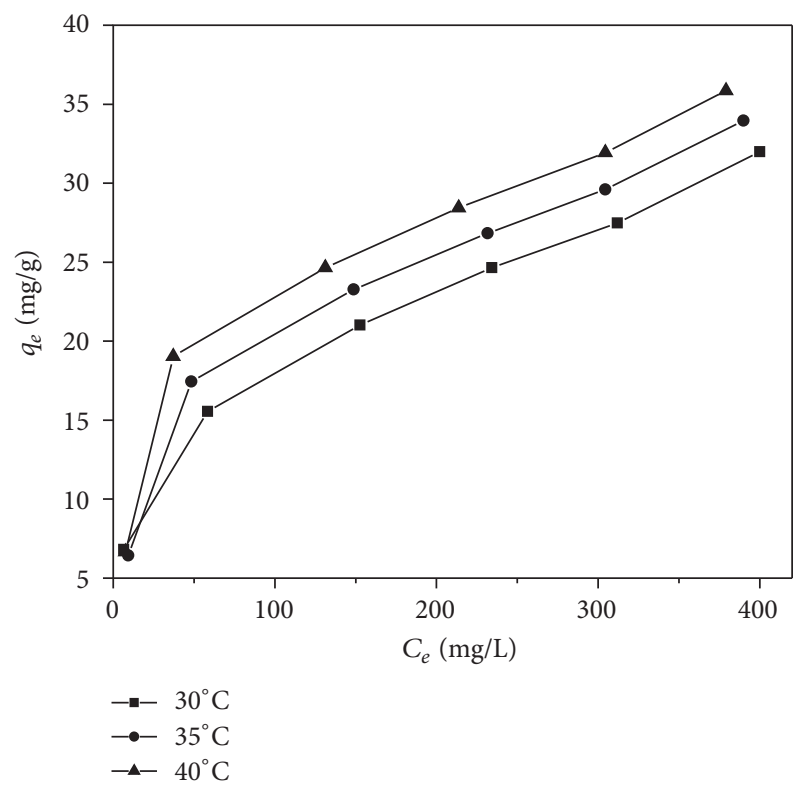

FIGURE 5: Adsorption isotherms of ammoniacal nitrogen on $\mathrm{X} / \mathrm{AC}$ composite.

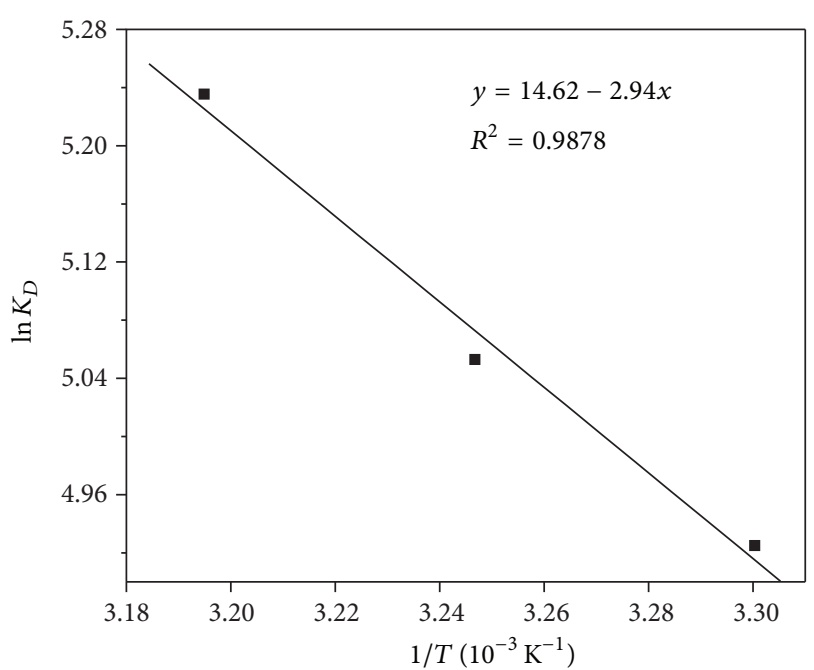

FIgURE 6: Plot of $\ln K_{D}$ versus $1 / T$ for ammoniacal nitrogen adsorption on $\mathrm{X} / \mathrm{AC}$ for thermodynamic parameters.

negative values of $\Delta G^{0}$ at higher temperatures for endothermic adsorption. The entropy change $\left(\Delta S^{0}\right)$ was calculated as $0.1215 \mathrm{~kJ} /(\mathrm{mol} \cdot \mathrm{K})$. The positive value of $\Delta S^{0}$ indicates the randomness at the solid/solution interface is related to the degree of freedom [19].

Generally, the values of $\Delta H^{0}$ are $0 \sim-20 \mathrm{KJ} / \mathrm{mol}$ and $-80 \sim-400 \mathrm{KJ} / \mathrm{mol}$ related to physical adsorption and chemical adsorption, respectively. The result in this work showed that the adsorption of ammoniacal nitrogen on the X/AC composite includes some chemisorption. The adsorption of ammoniacal nitrogen on the composite is attributed to ion exchange process. The values of $\Delta H^{0}$ are $2.1 \sim 20.9 \mathrm{~kJ} / \mathrm{mol}$ and $80 \sim 200 \mathrm{~kJ} / \mathrm{mol}$ indicating physical adsorption and chemical adsorption. The value of $\Delta H^{0}$ in Table 3 is higher than 20.9, indicating that adsorption of ammoniacal nitrogen on the composite is chemical adsorption. This result was in well agreement with $\Delta G^{0}$.

3.5. Adsorption Kinetics. In a typical adsorption experiment, $0.15 \mathrm{~g}$ of the composite was added in $25 \mathrm{~mL}$ ammonium 
TABLE 1: Isotherm parameters of ammoniacal nitrogen adsorption on X/AC at different temperatures.

\begin{tabular}{|c|c|c|c|c|}
\hline \multirow{2}{*}{ Isotherm model } & \multirow{2}{*}{ Isotherm constants } & \multicolumn{3}{|c|}{ Ammonium } \\
\hline & & $30^{\circ} \mathrm{C}$ & $35^{\circ} \mathrm{C}$ & $40^{\circ} \mathrm{C}$ \\
\hline \multirow{4}{*}{ Langmuir } & $q_{m}(\mathrm{mg} / \mathrm{g})$ & 35.04 & 35.50 & 35.91 \\
\hline & $b_{1}(\mathrm{~L} / \mathrm{mg})$ & 0.013 & 0.018 & 0.026 \\
\hline & $R^{2}$ & 0.9221 & 0.9571 & 0.9512 \\
\hline & RMSE & 1.76 & 1.96 & 2.29 \\
\hline \multirow{4}{*}{ Freundlich } & $K_{F}\left((\mathrm{mg} / \mathrm{g})(\mathrm{L} / \mathrm{mg})^{1 / n}\right)$ & 3.23 & 3.56 & 4.69 \\
\hline & $n$ & 0.38 & 0.37 & 0.34 \\
\hline & $R^{2}$ & 0.9936 & 0.9805 & 0.9681 \\
\hline & RMSE & 0.17 & 1.11 & 1.34 \\
\hline \multirow{5}{*}{ R-P } & $K_{R}(\mathrm{~L} / \mathrm{g})$ & $2.85 * 10^{5}$ & 1.83 & $1.21 * 10^{4}$ \\
\hline & $\alpha_{R}(\mathrm{~L} / \mathrm{mg})^{\beta}$ & $8.84 * 10^{4}$ & 0.28 & $2.6 * 10^{3}$ \\
\hline & $\beta$ & 0.62 & 0.73 & 0.67 \\
\hline & $R^{2}$ & 0.9936 & 0.9867 & 0.9681 \\
\hline & RMSE & 0.19 & 0.91 & 1.64 \\
\hline
\end{tabular}

TABLE 2: Thermodynamic parameters of ammoniacal nitrogen adsorption on $\mathrm{X} / \mathrm{AC}$.

\begin{tabular}{lccc}
\hline \multirow{2}{*}{ Temperature $/{ }^{\circ} \mathrm{C}$} & \multicolumn{3}{c}{ Ammoniacal nitrogen } \\
& $\Delta G^{0}(\mathrm{KJ} / \mathrm{mol})$ & $\Delta H^{0}(\mathrm{KJ} / \mathrm{mol})$ & $\Delta S^{0}(\mathrm{~J} /(\mathrm{mol} \cdot \mathrm{K}))$ \\
\hline 30 & -36.81 & & \\
35 & -37.41 & 24.44 & 121.55 \\
40 & -38.02 & & \\
\hline
\end{tabular}

solution in $100 \mathrm{~mL}$ beaker, at the temperature of $25^{\circ} \mathrm{C}$. After adsorption, the solution was separated from the adsorbent by centrifugation, and the concentration was analyzed. The figure of adsorption versus time is shown in Figure 7.

As shown in Figure 7, within $30 \mathrm{~min}$, the adsorption speed increased while the concentration of ammonium increased. The higher the concentration of ammonium is, the bigger the difference is between the concentration in solution and that in the adsorbent, which offers high driving force for ion exchange in the composite and speeds up the adsorption of ammonium. The adsorption speed slowed down until getting equilibrium from 30 to $120 \mathrm{~min}$. Figure 7 showed the uptakes of ammonium increased from 7.74 to $34.27 \mathrm{mg} / \mathrm{g}$ when the initial concentration of ammonium increased from $69 \mathrm{mg} / \mathrm{L}$ to $500 \mathrm{mg} / \mathrm{L}$. The adsorption got equilibrium because ion exchange reached equilibrium, at which point ammonium could not be removed anymore. The kinetic results are fitted by pseudofirst-order kinetic model and pseudosecond-order kinetic model, as shown in Figures 7(b) and 7(c) and Table 3.

A curve of $\ln \left(q_{e}-q_{t}\right)$ versus $t$ was fitted by the pseudofirstorder kinetic model and was shown in Figure 7(b). A curve of $t / q_{t}$ and $t$ was fitted by the pseudosecond-order kinetic model and was shown in Figure $7(\mathrm{c})$. The correlation coefficients $\left(R^{2}\right)$ are used to describe the applicability of the adsorption kinetics model. The $R^{2}$ values for the pseudofirst-order model are the lowest among the used models. The $R^{2}$ values are $0.8405,0.9517,0.6940,0.7841$, and 0.6982 , respectively. Moreover, the value of $q_{e(\exp )}$ differs significantly from that of $q_{e(\mathrm{cal})}$, which indicates the pseudofirst-order model does not work for the adsorption of ammonium by the X/AC model. It has been reported that the pseudofirst-order model fits better the adsorption in the early stage, but not the whole adsorption process.

However, the $R^{2}$ values for the pseudosecond-order kinetic model are higher than 0.999 for five different initial concentrations, and the values of $q_{e}(\exp )$ are very close to that of $q_{e}$ (cal), which indicates the pseudosecond-order kinetic model fit better the adsorption of ammonium by $\mathrm{X} / \mathrm{AC}$ than the pseudofirst order. On the other hand, the $q_{e}$ (cal.) value for the pseudofirst-order model is lower than the experimental adsorption capacity of ammoniacal nitrogen $\left(q_{e}(\exp ).\right)$, but the $q_{e}($ cal. $)$ value for the pseudosecondorder model is in agreement with $q_{e}$ (exp.) values. Generally, the pseudosecond-order model is proper to the adsorption kinetics.

In a water bath the temperatures were controlled at 298, 303 , and $308 \mathrm{~K}$; the adsorbent was added to the ammonium solution with a concentration of $65.50 \mathrm{mg} / \mathrm{L}$ and adsorbent to solution ratio of $6 \mathrm{~g} / \mathrm{L}$. The result is shown in Figure 8(a). The value of $K$ was calculated from the pseudosecond-order kinetic model. From Arrhenius equation, $\ln K=-\mathrm{Ea} / \mathrm{RT}+$ $\ln A$. The curve of $\ln K$ versus $1 / T$ is shown in Figure $8(\mathrm{~b})$. From the slope of the linear fitting, the active energy of adsorption Ea was calculated to be $47.74 \mathrm{KJ} / \mathrm{mol}$. The activation energy of adsorption Ea for physical adsorption is $5 \sim 40 \mathrm{KJ} / \mathrm{mol}$, while the activation energy of adsorption Ea for chemical adsorption is $40 \sim 800 \mathrm{KJ} / \mathrm{mol}$. Thus, the adsorption of ammoniacal nitrogen on the composite is chemical adsorption.

\section{Conclusions}

In this work, it is demonstrated that the zeolite $\mathrm{X} /$ activated carbon composite originated from elutrilithe is an effective adsorbent for the removal of ammoniacal nitrogen. The adsorption equilibrium, thermodynamic, and kinetics parameters for the adsorption process have been investigated. Compared with Langmuir adsorption isotherm, the equilibrium adsorption data were better described by Freundlich 
TABLE 3: Kinetics parameters for ammoniacal nitrogen adsorption on X/AC.

\begin{tabular}{|c|c|c|c|c|c|c|c|}
\hline \multirow[b]{2}{*}{$C_{0}(\mathrm{mg} / \mathrm{L})$} & \multirow{2}{*}{$\begin{array}{l}q_{e(\exp )} \\
(\mathrm{mg} / \mathrm{g})\end{array}$} & \multicolumn{3}{|c|}{ Pseudofirst order } & \multicolumn{3}{|c|}{ Pseudosecond order } \\
\hline & & $\begin{array}{c}q_{e(\mathrm{cal})} \\
(\mathrm{mg} / \mathrm{g})\end{array}$ & $K_{1}\left(\min ^{-1}\right)$ & $R^{2}$ & $\begin{array}{l}q_{e(\mathrm{cal})} \\
\mathrm{mg} / \mathrm{g}\end{array}$ & $K_{2}\left(\min ^{-1}\right)$ & $R^{2}$ \\
\hline 69 & 7.52 & 1.45 & $2.2 * 10^{-2}$ & 0.8405 & 7.78 & $6.55 * 10^{-2}$ & 0.9997 \\
\hline 122 & 14.45 & 1.98 & $3.6 * 10^{-2}$ & 0.9517 & 14.56 & $6.56 * 10^{-2}$ & 0.9999 \\
\hline 280 & 30.59 & 1.35 & $6.1 * 10^{-3}$ & 0.6940 & 30.81 & $4.41 * 10^{-2}$ & 0.9999 \\
\hline 460 & 32.96 & 1.47 & $2.0 * 10^{-2}$ & 0.7841 & 32.95 & $7.23 * 10^{-2}$ & 0.9999 \\
\hline 500 & 34.43 & 1.64 & $2.0 * 10^{-2}$ & 0.6982 & 34.36 & $5.76 * 10^{-2}$ & 0.9999 \\
\hline
\end{tabular}

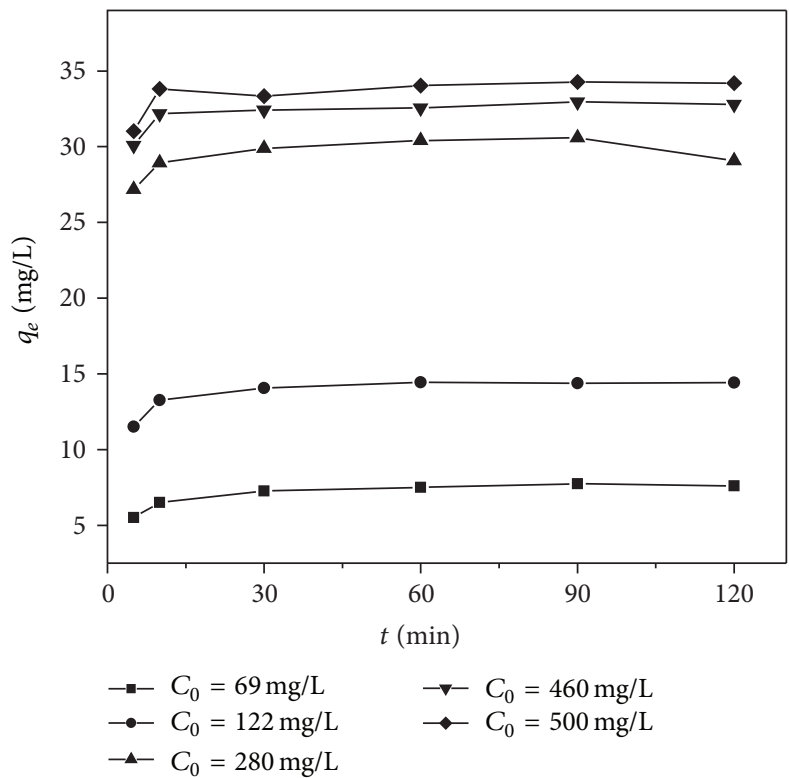

(a)

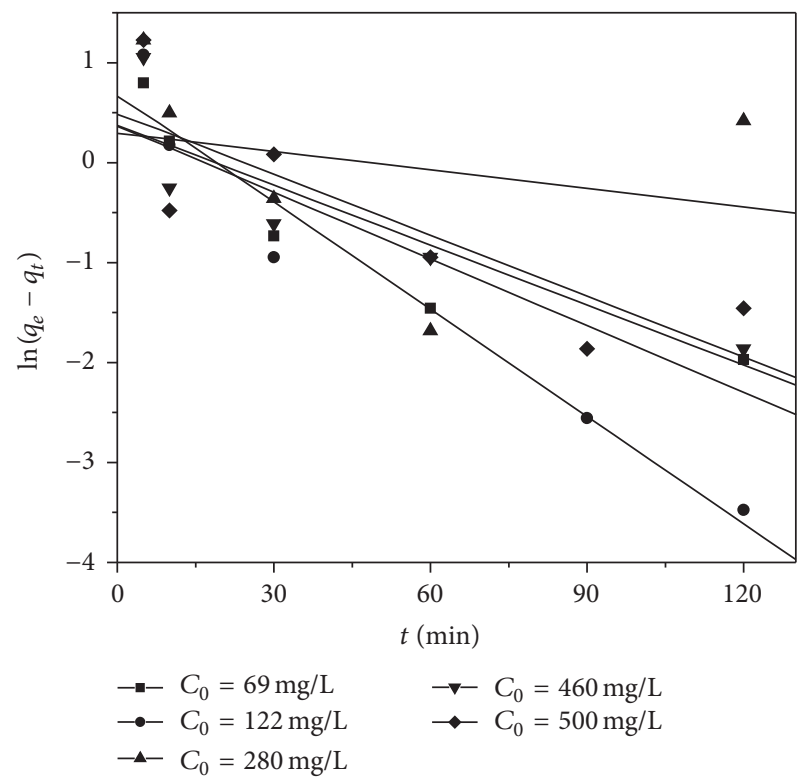

(b)

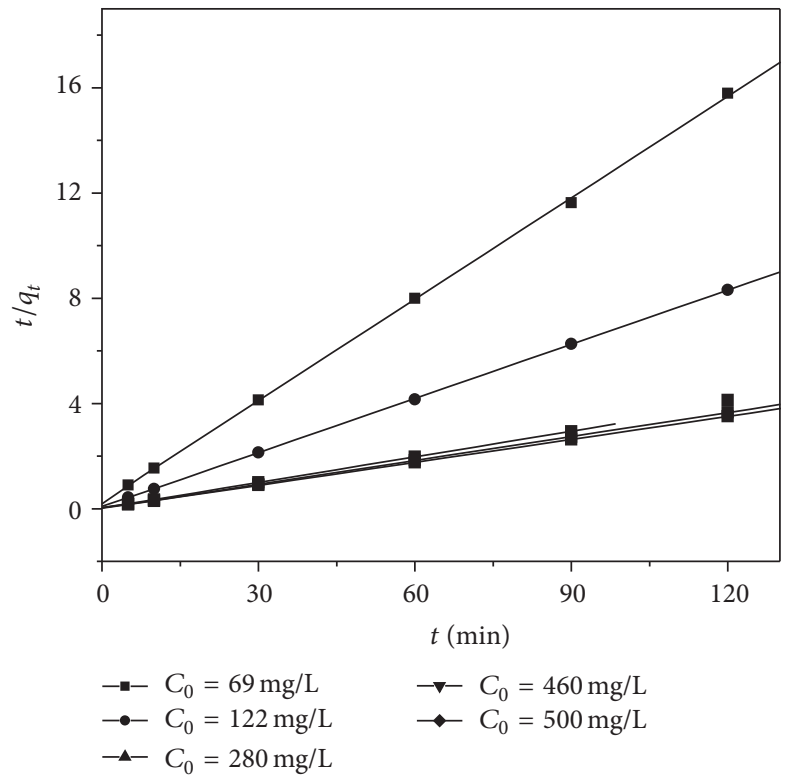

(c)

FIGURE 7: Adsorption kinetics of ammonium from aqueous solution: (a) effect of contact time on ammonium adsorption, (b) pseudofirstorder kinetic model, and (c) pseudosecond-order kinetic model. 


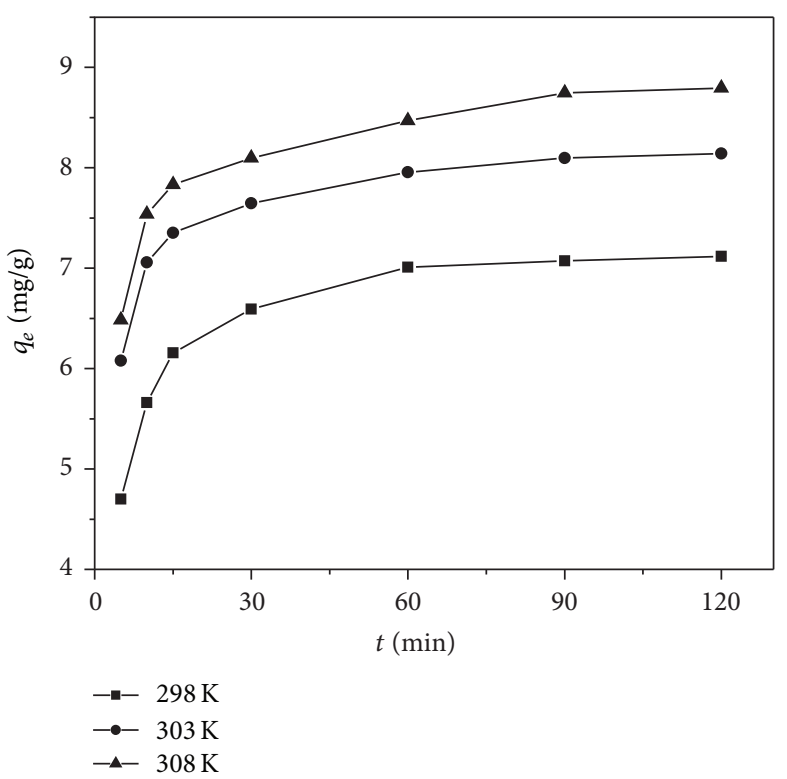

(a)

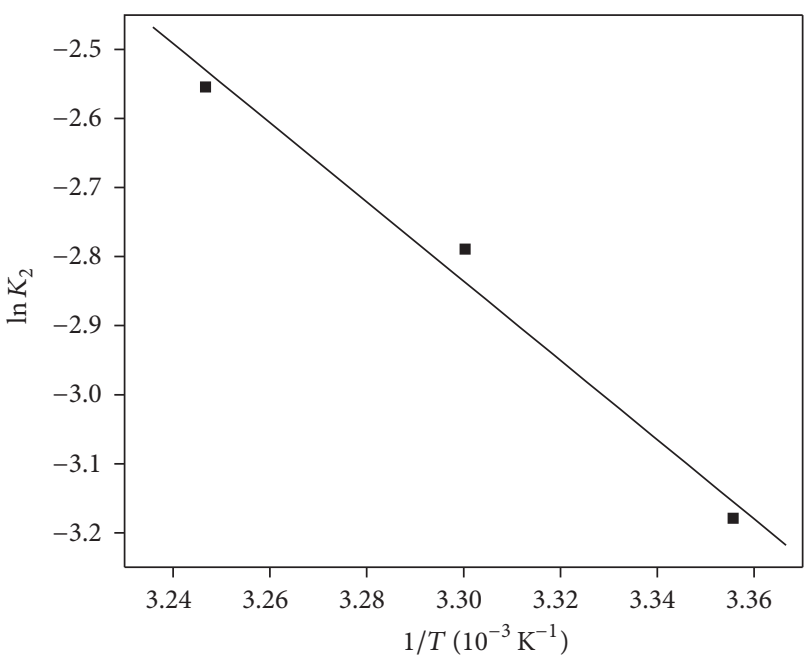

(b)

FIGURE 8: The activation energy of ammonia adsorption on X/AC (a) and plot of $\ln k$ versus $1 / T$ (b).

models and the Redlich-Peterson. The thermodynamic properties of ammoniacal nitrogen adsorption concluded that the process was spontaneous and endothermic process by the adsorption of X/AC. The adsorption kinetics is best depicted by the pseudosecond-order model, indicating the adsorption process is chemisorption. This material has a significant potential in removing ammoniacal nitrogen coexisting with other organic compounds from industrial wastewater.

\section{Conflicts of Interest}

The authors declare that there are no conflicts of interest regarding the publication of this paper.

\section{Acknowledgments}

The authors gratefully appreciate the financial support from the National Science Foundation of China (nos. 51204120, 51579168, and 51409184), Scientific and Technological Project of Shanxi Province (no. 20140311016-6), and Natural Science Foundation of Shanxi (no. 2014021014-1). Also, the authors gratefully acknowledge Professor J. Ma and R. Li for their usefully discussion.

\section{References}

[1] D. Pathania, G. Sharma, and R. Thakur, "Pectin @ zirconium (IV) silicophosphate nanocomposite ion exchanger: photo catalysis, heavy metal separation and antibacterial activity," Chemical Engineering Journal, vol. 267, pp. 235-244, 2015.

[2] G. Sharma, M. Naushad, D. Pathania, A. Mittal, and G. E. El-desoky, "Modification of Hibiscus cannabinus fiber by graft copolymerization: application for dye removal," Desalination and Water Treatment, vol. 54, no. 11, pp. 3114-3121, 2015.

[3] S. Karthikeyan, M. Anil Kumar, P. Maharaja, T. Partheeban, J. Sridevi, and G. Sekaran, "Process optimization for the treatment of pharmaceutical wastewater catalyzed by poly sulpha sponge," Journal of the Taiwan Institute of Chemical Engineers, vol. 45, no. 4, pp. 1739-1747, 2014.

[4] A. Mittal, M. Naushad, G. Sharma, Z. A. Alothman, S. M. Wabaidur, and M. Alam, "Fabrication of MWCNTs/ThO nanocomposite and its adsorption behavior for the removal of $\mathrm{Pb}$ (II) metal from aqueous medium," Desalination and Water Treatment, vol. 57, no. 46, pp. 21863-21869, 2016.

[5] T. Vidhyadevi, A. Murugesan, S. S. Kalaivani et al., "Optimization of the process parameters for the removal of reactive yellow dye by the low cost Setaria verticillata carbon using response surface methodology: thermodynamic, kinetic, and equilibrium studies," Environmental Progress \& Sustainable Energy, vol. 33, no. 3, pp. 855-865, 2014.

[6] D. Pathania, D. Gupta, A. H. Al-Muhtaseb et al., "Photocatalytic degradation of highly toxic dyes using chitosan-gpoly(acrylamide)/ZnS in presence of solar irradiation," Journal of Photochemistry and Photobiology A: Chemistry, vol. 329, pp. 61-68, 2016.

[7] H. Zheng, L. Han, H. Ma et al., "Adsorption characteristics of ammonium ion by zeolite 13X," Journal of Hazardous Materials, vol. 158, no. 2-3, pp. 577-584, 2008.

[8] D. J. Randall and T. K. N. Tsui, "Ammonia toxicity in fish," Marine Pollution Bulletin, vol. 45, no. 1-12, pp. 17-23, 2002.

[9] N. Öztürk and T. E. Bektaş, "Nitrate removal from aqueous solution by adsorption onto various materials," Journal of Hazardous Materials, vol. 112, no. 1-2, pp. 155-162, 2004.

[10] L. A. Schipper and M. Vojvodić-Vuković, "Five years of nitrate removal, denitrification and carbon dynamics in a denitrification wall," Water Research, vol. 35, no. 14, pp. 3473-3477, 2001. 
[11] K. Abe, A. Imamaki, and M. Hirano, "Removal of nitrate, nitrite, ammonium and phosphate ions from water by the aerial microalga Trentepohlia aurea," Journal of Applied Phycology, vol. 14, no. 2, pp. 129-134, 2002.

[12] B.-U. Bae, Y.-H. Jung, W.-W. Han, and H.-S. Shin, "Improved brine recycling during nitrate removal using ion exchange," Water Research, vol. 36, no. 13, pp. 3330-3340, 2002.

[13] D. Wu, B. Zhang, C. Li, Z. Zhang, and H. Kong, "Simultaneous removal of ammonium and phosphate by zeolite synthesized from fly ash as influenced by salt treatment," Journal of Environmental Sciences, vol. 19, no. 5, pp. 300-306, 2007.

[14] M. Sprynskyy, M. Lebedynets, A. P. Terzyk, P. Kowalczyk, J. Namieśnik, and B. Buszewski, "Ammonium sorption from aqueous solutions by the natural zeolite Transcarpathian clinoptilolite studied under dynamic conditions," Journal of Colloid \& Interface Science, vol. 284, no. 2, pp. 408-415, 2005.

[15] M. Rožić, Š. Cerjan-Stefanović, S. Kurajica, V. Vančina, and E. Hodžić, "Ammoniacal nitrogen removal from water by treatment with clays and zeolites," Water Research, vol. 34, no. 14, pp. 3675-3681, 2000.

[16] J.-Y. Jung, Y.-C. Chung, H.-S. Shin, and D.-H. Son, "Enhanced ammonia nitrogen removal using consistent biological regeneration and ammonium exchange of zeolite in modified SBR process," Water Research, vol. 38, no. 2, pp. 347-354, 2004.

[17] Y. Takami, N. Murayama, K. Ogawa, H. Yamamoto, and J. Shibata, "Water purification property of zeolite synthesized from coal fly ash," Shigen-to-Sozai, vol. 116, no. 9, pp. 789-794, 2000.

[18] M. Zhang, H. Zhang, D. Xu et al., "Removal of ammonium from aqueous solutions using zeolite synthesized from fly ash by a fusion method," Desalination, vol. 271, no. 1-3, pp. 111-121, 2011.

[19] D. Karadag, Y. Koc, M. Turan, and B. Armagan, "Removal of ammonium ion from aqueous solution using natural Turkish clinoptilolite," Journal of Hazardous Materials, vol. 136, no. 3, pp. 604-609, 2006.

[20] H. M. Huang, X. M. Xiao, B. Yan, and L. P. Yang, "Ammonium removal from aqueous solutions by using natural Chinese (Chende) zeolite as adsorbent," Journal of Hazardous Materials, vol. 175, no. 1-3, pp. 247-252, 2010.

[21] A. M. Yusof, L. K. Keat, Z. Ibrahim, Z. A. Majid, and N. A. Nizam, "Kinetic and equilibrium studies of the removal of ammonium ions from aqueous solution by rice husk ashsynthesized zeolite $\mathrm{Y}$ and powdered and granulated forms of mordenite," Journal of Hazardous Materials, vol. 174, no. 1-3, pp. 380-385, 2010.

[22] T. Mishra and S. K. Tiwari, "Studies on sorption properties of zeolite derived from Indian fly ash," Journal of Hazardous Materials, vol. 137, no. 1, pp. 299-303, 2006.

[23] Z. Li, X. Cui, J. Ma, W. Chen, W. Gao, and R. Li, "Preparation of granular X-type zeolite/activated carbon composite from elutrilithe by adding pitch and solid $\mathrm{SiO}_{2}$," Materials Chemistry and Physics, vol. 147, no. 3, pp. 1003-1008, 2014.

[24] L. Yang and Z. Wang, "Research and application on renewable resources coal gangue," China Resources Comprehensive Utilization, vol. 25, no. 3, pp. 15-16, 2007.

[25] J. Ma, J. Tan, X. Du, and R. Li, "Effects of preparation parameters on the textural features of a granular zeolite/activated carbon composite material synthesized from elutrilithe and pitch," Microporous and Mesoporous Materials, vol. 132, no. 3, pp. 458463, 2010.
[26] K. Y. Foo and B. H. Hameed, "The environmental applications of activated carbon/zeolite composite materials," Advances in Colloid and Interface Science, vol. 162, no. 1-2, pp. 22-28, 2011.

[27] W. P. Cheng, W. Gao, X. Cui, J. H. Ma, and R. F. Li, "Phenol adsorption equilibrium and kinetics on zeolite X/activated carbon composite," Journal of the Taiwan Institute of Chemical Engineers, vol. 62, pp. 192-198, 2016.

[28] J. Ma, C. Si, Y. Li, and R. Li, " $\mathrm{CO}_{2}$ adsorption on zeolite $\mathrm{X} /$ activated carbon composites," Adsorption, vol. 18, no. 5-6, pp. 503-510, 2012.

[29] W. G. Walter, "APHA standard methods for the examination of water and wastewater," American Journal of Public Health \& The Nations Health, 1961.

[30] I. Langmuir, "The adsorption of gases on plane surfaces of glass, mica and platinum," The Journal of the American Chemical Society, vol. 40, no. 9, pp. 1361-1403, 1918.

[31] H. Freundlich, "Über die adsorption in lösungen," Zeitschrift für Physikalische Chemie, vol. 62, no. 5, pp. 121-125, 1906.

[32] O. Redlich and D. L. Peterson, "A useful adsorption isotherm," Journal of Physical Chemistry, vol. 63, no. 6, p. 1024, 1959.

[33] S. Lagergren, "About the theory of so-called adsorption of soluble substances," Kungliga Svenska Vetenskapsakademiens Handlingar, vol. 24, no. 4, pp. 1-39, 1898.

[34] Y. S. Ho and G. McKay, "Kinetic models for the sorption of dye from aqueous solution by wood," Process Safety and Environmental Protection, vol. 76, no. 2, pp. 183-191, 1998.

[35] J.-M. Lv, Y.-L. Ma, X. Chang, and S.-B. Fan, "Removal and removing mechanism of tetracycline residue from aqueous solution by using Cu-13X," Chemical Engineering Journal, vol. 273, pp. 247-253, 2015.

[36] Y. Zhao, B. Zhang, X. Zhang, J. Wang, J. Liu, and R. Chen, "Preparation of highly ordered cubic NaA zeolite from halloysite mineral for adsorption of ammonium ions," Journal of Hazardous Materials, vol. 178, no. 1-3, pp. 658-664, 2010.

[37] E. Marañón, M. Ulmanu, Y. Fernández, I. Anger, and L. Castrillón, "Removal of ammonium from aqueous solutions with volcanic tuff," Journal of Hazardous Materials, vol. 137, no. 3, pp. 1402-1409, 2006.

[38] K. Emerson, R. C. Russo, R. E. Lund, and R. V. Thurston, "Aqueous ammonia equilibrium calculations: effect of $\mathrm{pH}$ and temperature," Journal De Loffice Des Recherches Sur Les Pêcheries Du Canada, vol. 32, no. 12, pp. 2379-2383, 2011.

[39] N. Widiastuti, H. Wu, H. M. Ang, and D. Zhang, "Removal of ammonium from greywater using natural zeolite," Desalination, vol. 277 , no. $1-3$, pp. 15-23, 2011. 

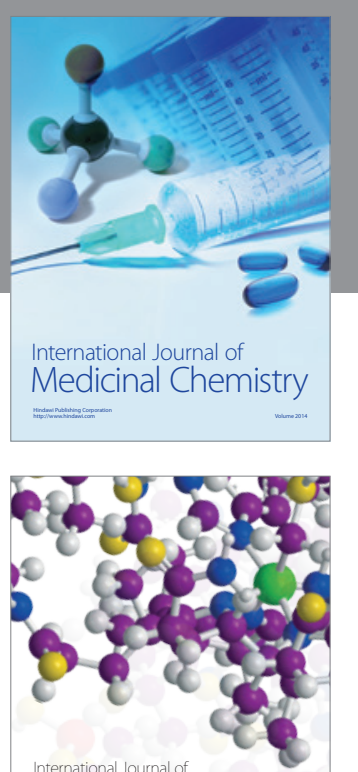

Carbohydrate Chemistry

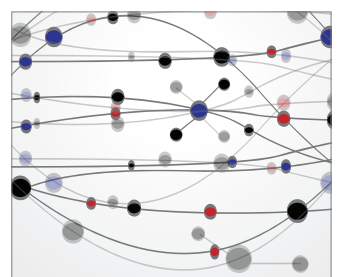

The Scientific World Journal
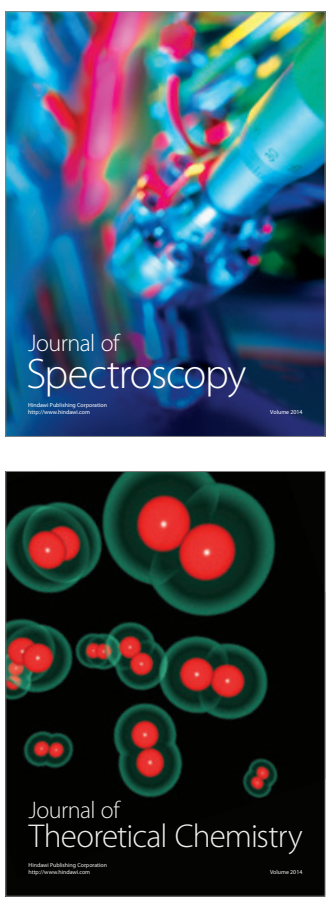
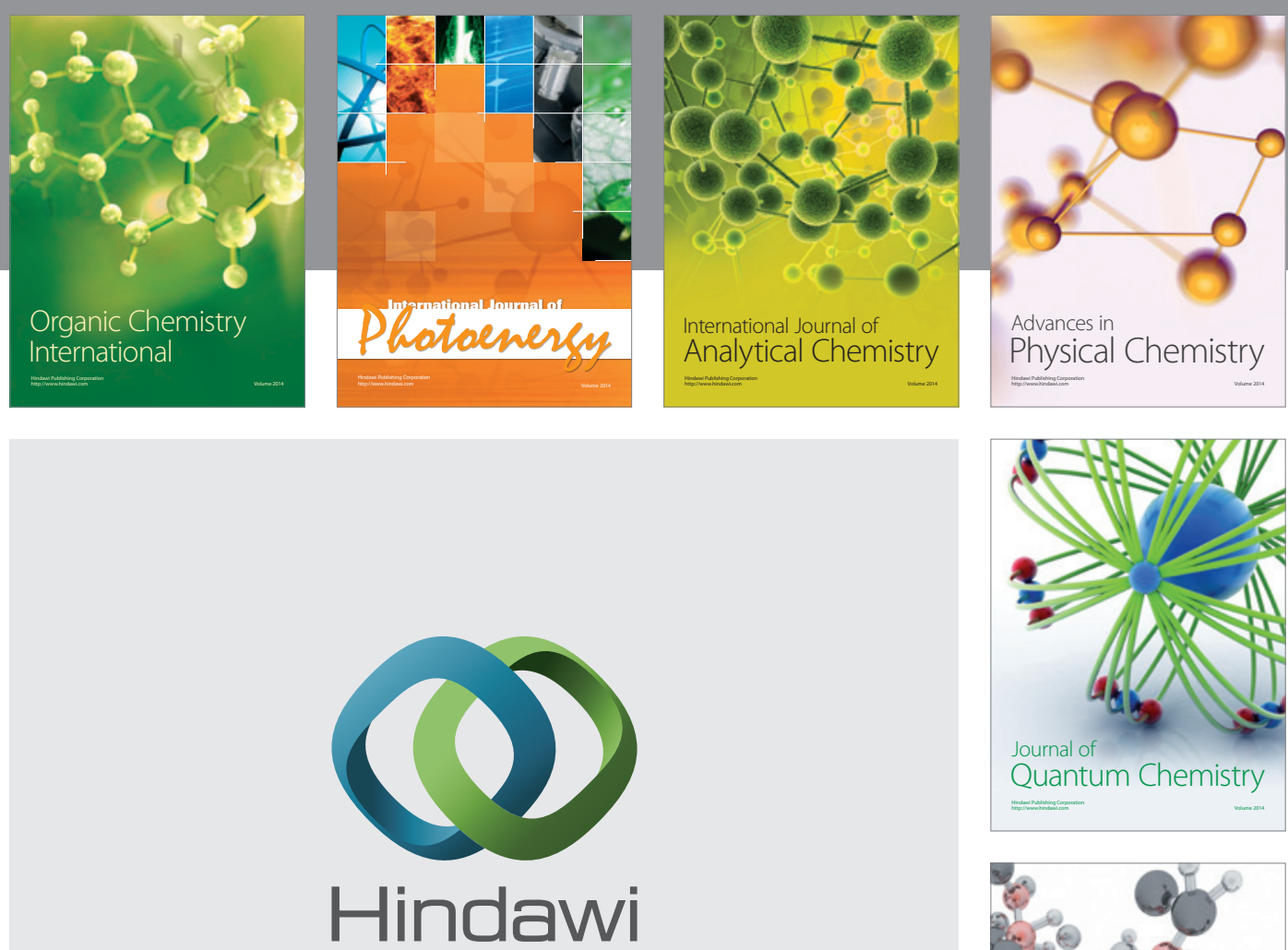

Submit your manuscripts at

https://www.hindawi.com

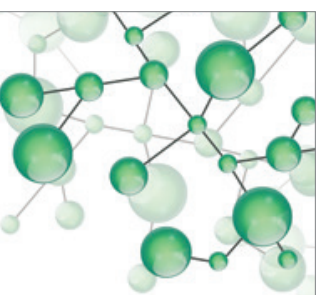

International Journal of

Inorganic Chemistry
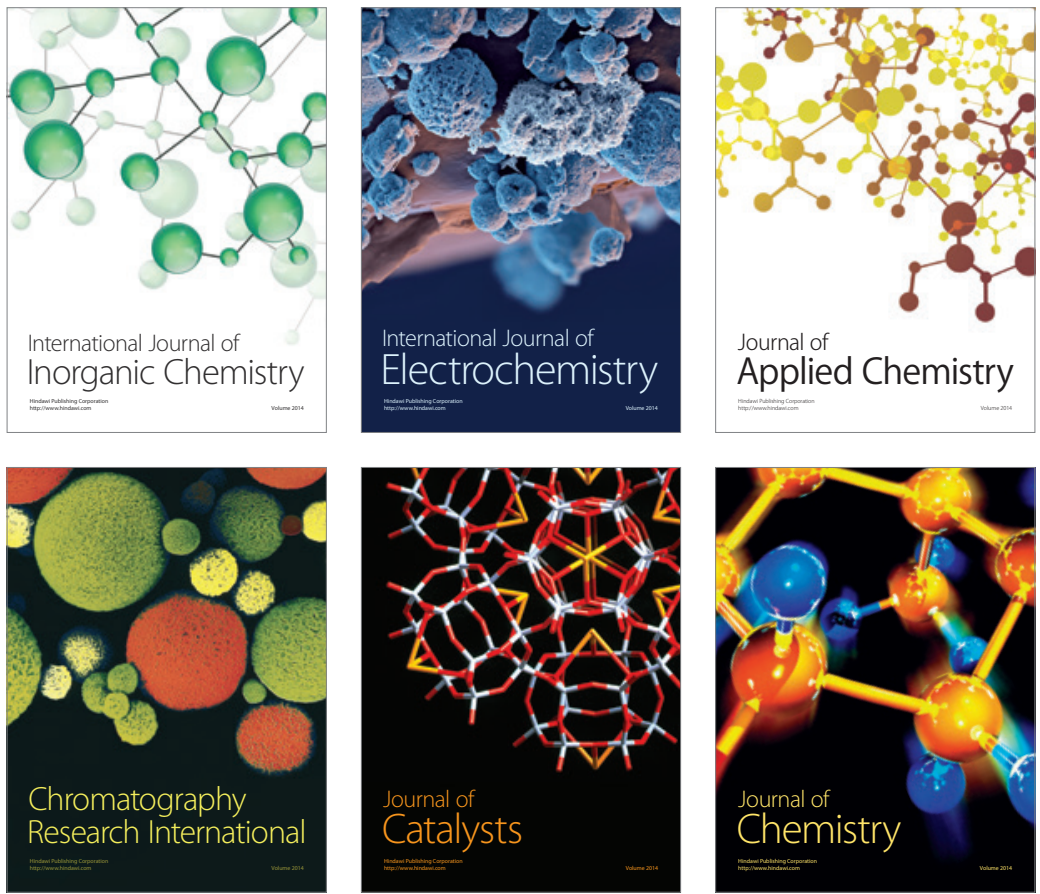

Journal of

Applied Chemistry
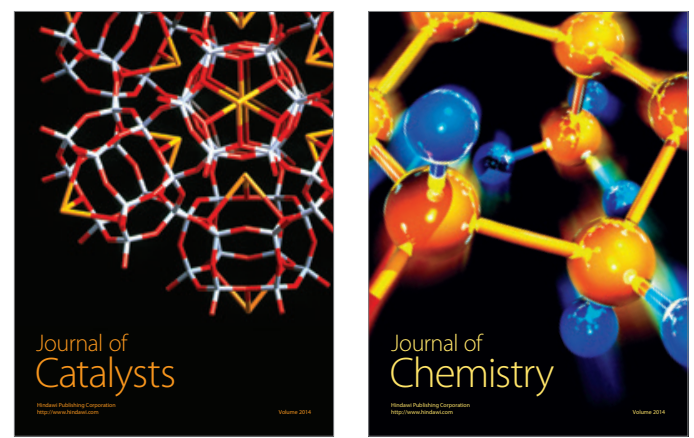
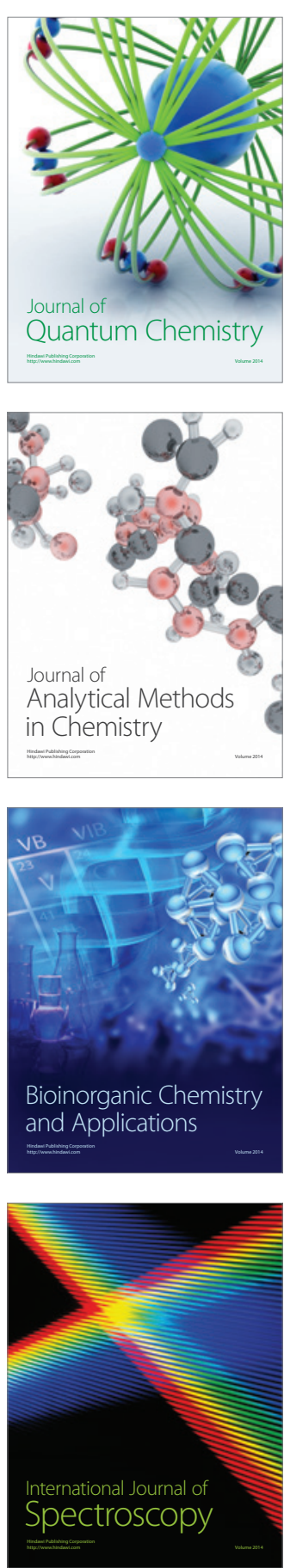